\title{
The Impact of Environmental, Social, and Governance Performance on Firm Risk in the ASEAN-5 Countries, 2011-2017
}

\begin{abstract}
Anindita Nur Annisa, Dwi Hartanti*
Department of Accounting, Universitas Indonesia, Depok, Indonesia

*Corresponding author. Email: dwi.hartanti71@ui.ac.id

ABSTRACT

This study examines the effect of environmental, social, and governance (ESG) performance on firm risk in South East Asia. The ESG performance is measured using the Thomson Reuter's ESG Score, which is further classified into the ESG Score, the ESG Controversy Score, and the ESG Combined Score. The risk is measured using total risk, systematic risk, and idiosyncratic risk. Employing 145 firms in ASEAN-5 countries namely Indonesia, Malaysia, Thailand, the Philippines, and Singapore as samples for the period 2011-2017, it is found that the ESG performance has a significant inverse effect on firm risk after controlling for the law enforcement difference in each country and other control variables. The ESG performance significantly affects total risk and idiosyncratic risk, but not systematic risk. There is also no effect found for the ESG Controversy Score, which acts as the proxy for a firm's involvement in controversial events related to ESG-on any proxy of risk. Overall, these findings support the previous studies in other regions that an increase in a firm's ESG performance could lower firm risk.
\end{abstract}

Keywords: ESG score, firm risk, systematic risk, idiosyncratic risk

\section{INTRODUCTION}

In recent years, there has been a growing interest in sustainability issues around the globe. Sustainability issues can be disruptive threats to any level of entities, be it individual, business, nation, or even global. These sustainability issues are now translated into a term called ESG, which stands for Environmental, Social, and Governance. Both investors and firms now consider ESG aspects in their decision making. We can see this from the increasing number of sustainability reports disclosed by firms. There used to be only 48 firms that issued sustainability reports, but the number had grown to 12,075 at the end of 2017. Along with this trend, studies and surveys have been conducted that examine the implications of such sustainability efforts by firms and investors.

A survey from Ernst \& Young in 2017 (Nelson, 2017) implies that ESG are strongly related to both risk and opportunity. ESG can help firms identify new opportunities and manage its investment risks for the long term; it can also help avoid bad firm performance caused by poor governance of environmental and social practices. Albuquerque, Koskinen, and Zhang (2017) also found that firms that are engaged with social or ESG activities can lower their systematic risk and increase the firm value. A review of 200 academic research articles and books was conducted, and $88 \%$ of the studies conclude that good ESG practices would lead to better operational performance. Although there has been much concern over whether investing in sustainability efforts would reduce financial performance returns, recent studies found that putting efforts into sustainability would only create value for the firm and increase the firm's return on assets (ROA), and return on equity (ROE) (Lee, Cin, \& Lee, 2016; Mcphail, 2014; Mentor, 2016). As for investors, from the survey conducted by Ernst \& Young in 2017 (Nelson, 2017), we can see a growing proportion of investors deciding that nonfinancial information-such as 
a firm's sustainability information-is becoming more important. There has been a growing body of evidence that proves ESG investment returns to be higher than conventional investment (Patel, 2015).

It is easier to find literature that examines the relationship between ESG performance and a firm's financial performance. However, to find a study that examines the effect of ESG performance on market risk has been difficult (MSCI, 2018). There has also been limited research on this topic in developing countries, while they are actually are more vulnerable to ESG threats such as climate change and lawsuits resulting from social issues compared to the developed countries (Maisonneuve, 2017). This research tried to fill those gaps by investigating the impact of ESG performance on firm market risk because firm market risk (hereafter, firm risk) will affect how investors make investment decisions. Specifically, this research will also investigate the impact of a firm's involvement in ESG controversial issues to firm risk. This research is going to be focused on South East Asia because, as one of the fastest-growing emerging markets in the world, it carries much potential as well as many threats.

We used a panel dataset of 995 firm-year observations during 2011-2017 to examine the effect of ESG performance on several risk measures: total risk, systematic risk, and idiosyncratic risk. The total risk reflects the firm's stock volatility. The systematic risk reflects the sensitivity of firm stock to market movement. The idiosyncratic risk reflects firm-specific risks that are related to firm strategy and not affected by the market. The risk ratios were taken from the Thomson Reuters Datastream database, while the ESG factors were obtained from the Thomson Reuters ESG Research database. Three measures of ESG were used in this research: ESG Score, ESG Controversy Score, and ESG Combined Score. By performing random effect regressions, we provide evidence that ESG performance negatively affects total risk and idiosyncratic risk, while there are no relationships found for systematic risk. In addition, there is no relationship found between a firm's involvement in ESG controversial issues with firm risk.

\section{LITERATURE REVIEW AND HYPOTHESIS DEVELOPMENT}

\subsection{Background}

In recent years, we have witnessed a growing interest in sustainability aspects from all around the globe. This has received even more attention with the emergence of Sustainable Development Goals which emphasize sustainable issues in every aspect of life. The major attention-gathering sustainability issues are ESG issues. The increasing number of sustainability issues has also been followed by the ever-increasing amount of sustainability reporting that displays a company's sustainability performance over a year. In 2000, there were only 48 organizations that were submitted in the Global Reporting Initiatives. This number grew to 12,075 organizations by the end of 2017 (Global Reporting Initiative, 2018).

In this study, we investigated the motivations these organizations or businesses have for reporting their sustainability efforts. In addition, it is important to determine what drives these organizations to put effort into the sustainability aspects of their businesses. From a theoretical perspective, this recent trend contradicts stakeholder theory or even shareholder theory. Stakeholder theory explains that the aim of a business is to serve and fulfill the interest of its stakeholders (Abdullah $\&$ Valentine, 2009). Shareholder theory argues that the aim of a business is to maximize its shareholders' value (Saint \& Tripathi, 2006). The recent trend seems to cross the two theories. Enlightened value maximization theory, which was initiated by Jensen (2001), emerged as critical of these theories. It argues that shareholder theory and stakeholder theory are not mutually exclusive. The theory further explains that it is possible for a firm to aim for both maximization of shareholder value and the fulfillment of stakeholders' interests at the same time. From the perspective of this theory, if a firm integrates ESG (for fulfilling the stakeholders' interest) into its strategy, it would create a competitive advantage that would maximize firm value in the long term. Another theory that can answer the question is business ethics theory, which argues that a firm's ESG efforts through corporate social responsibility do not guarantee that a firm is ethical. To be an ethical one, a firm must integrate ESG into its strategy.

From an empirical perspective, one study found that investing in sustainability will give an entity competitive advantage through risk reduction, increased performance, and a managed reputation (Clark, Feiner, \& Viehs, 2015). The study also found that $88 \%$ of the reviewed literature also shows that good ESG practices would lead to improvement in an entity's operational performance. An organization also wants to maintain its reputation to its stakeholders, which include its investors. Many investors are now considering ESG aspects when making their investment decisions. This is now called by its own term, ESG investing. In making investment decisions, ESG investors are equipped with information from available ESG sources, such as sustainable reports, annual reports, the ESG Index, etc. The reasons behind the rise of ESG 
investing are (1) integrating ESG aspects into an investment to generate a better return (2) the investor's own values, and (3) the hope that ESG would create a positive impact on firm performance (MSCI, 2018). This trend was also strengthened by the UN Principles of Responsible Investment (UNPRI) that primarily increase the trend of ESG investing in Europe. Despite its popularity in Europe and the Western countries, developing countries have been rather slow to adopt UNPRI (Maisonneuve, 2017). This is contradictory to the fact that developing countries are the ones that are more vulnerable to the threats originating from ESG issues.

South East Asia is a region that contains developing countries with considerably high growth rates. These countries are included in the Association of South East Asian Nations (ASEAN). ASEAN region, with 67 million households which some of it is a consuming class, emerge as an economic powerhouse. The region is ranked as the seventh largest economy in the world when combined (Thompson, Tonby, \& Vinayak, 2014). It is the fourth largest exporter in the world, with $7 \%$ of global exports. Even the ASEAN leading countries namely Malaysia, Indonesia, the Philippines, Thailand, and Singapore attract more foreign investment. However, with its enormous potential, business in ASEAN also has the potential for disruption and risk. There are issues like pollution, water scarcity, and labor issues - not to mention climate change, which specifically threatens ASEAN countries that lie on the equator and have long shorelines. A recent survey showed that, according to 1.200 companies around the world, the uppermost business risk is business interruption. This includes nonphysical disruption caused by political situations, terrorism, or even climate change. Therefore, both firms and investors must pay extra attention to these potential risks. Any risks that must be faced by a firm or any events that can happen to a firm will later be reflected in firm risk (Beaver, Kettler, \& Scholes, 1970).

\subsection{The Link between ESG and Firm Risk}

Previous research has provided evidence that good ESG performance can lower firm financial risk (Orlitzky \& Benjamin, 2001). Plumlee, Brown, Hayes, \& Marshall, 2015) also argued that high ESG performance could potentially increase shareholder's value because a lower firm risk could create lower capital cost. It was also found that better ESG performance positively impacts employees' and investors' attitudes toward the firm, thus affecting the firm's reputation and lowering firm risk (Luo $\&$ Bhattacharya, 2009). This research further argued that the better the ESG performance of a firm is compared to its competitor's, the better firm's reputation is in the eyes of its stakeholders. In addition, better ESG performance could help firms build the strength to face any possibilities of loss of economic value in the future, which could lessen the risk or the vulnerability of cash flow in the future. Miralles-quir, Miguel, \& Gon, (2018) argued that integrating ESG into corporate strategy would create competitive advantages that promote the creation of longterm shareholder value. This competitive advantage includes increased reputation, increased employee productivity, increased operational efficiency, better relationships with regulators, society, and other stakeholders, which would open access to better investment projects and more diverse financial sources (Miralles-quir et al., 2018). Additionally, Kumar, Smith, Badis, Wang, Ambrosy, \& Tavares (2016) also found that firms that integrate ESG factors into their strategy display lower stock volatility-hence, firm market riskcompared to their peers in the same industry.

Given the predominance of arguments, we assumed that ESG performance would have negative relationships with all firm risk measures. Since a firm's involvement in ESG controversial issues can also reflect its ESG performance, we also suspected the same result: that ESG controversy would have a negative relationship with all firm risk measures. This led us to our first hypotheses:

Hla: ESG Combined Score negatively affects total risk.

\section{HIb: ESG Score negatively affects total risk.}

Orlitzky \& Benjamin (2001) also found that corporate social responsibility (CSR) reputation affects firm risk. Furthermore, the ESG reputation of a firm is affected by media reports about the firm's involvement in controversial issues, thus exacerbating firm risk. While the ESG Controversy Score is getting higher, firm will be more controversial. This led to an additional hypothesis:

\section{H1c: ESG Controversy Score positively affects total risk.}

Some studies have also examined the relationship between ESG performance with systematic risk, and they have proved that ESG performance also negatively affects systematic risk (Albuquerque et al., 2017; Jo \& Na, 2012; Luo, \& Bhattacharya, 2009; Orlitzky \& Benjamin, 2001). Sassen, Hinze, and Hardeck (2016) also found that social performance has a negative correlation with systematic risk, while environmental performance only negatively affects firm risk in environmentally sensitive industries. Given these arguments, we assumed that ESG performance has a negative relationship with systematic risk. We also suspected that the firm's involvement in ESG controversial issues would increase the risk, just like 
in the previous hypotheses. This led us to our second set of hypotheses.

\section{H2a: ESG Combined Score performance negatively affects systematic risk.}

\section{H2b: ESG Score performance negatively affects systematic risk.}

\section{H2c: ESG Controversy Score positively affects systematic risk.}

Benlemlih, Qiu, Shaukat, West, and Court (2016) and Boutin-Dufresne and Savaria (2004) argued that the use of idiosyncratic risk to examine the correlation between ESG performance with financial risk is relevant because idiosyncratic risk could probably capture the specific effect related to the firm's ESG strategy. In their study, Goyal \& Santa-Clara (2001) also found that $85 \%$ of firm risk is idiosyncratic risk, while the rest is systematic risk. This makes the use of idiosyncratic risk in this study relevant. Previous studies have also proven that higher ESG performance could lower total and idiosyncratic risk (Benlemlih et al., 2016; Luo \& Bhattacharya, 2009; Sassen et al., 2016). Thus, we assumed that ESG performance also has a negative relationship with systematic risk. Following the previous hypotheses, we also predicted that ESG controversial issues would exacerbate firm risk. This leads us to our third hypothesis:

H3a: ESG Combined Score performance negatively affects idiosyncratic risk,

H3b: ESG Score performance negatively affects idiosyncratic risk,

H3c: ESG Controversy Score positively affects idiosyncratic risk.

\section{RESEARCH METHODOLODY}

\subsection{Samples}

We chose South East Asia (SEA) as the locus of our research because no previous research showed any studies linking ESG performance to the three market risk measures within the South East Asia context. Most of the research on this topic has been done in Western countries like the study by Benlemlih et. al. (2016) in the United Kingdom and Sassen et al. (2016) in Europe. Moreover, the status that SEA bears as having the fast-growing emerging markets also emphasizes the importance of conducting research on such topics in this region.

The sample for this research consisted of all publicly listed SEA firms that already had their own ESG scoring from Thomson Reuters ESG Research. The period used in this research was from 2011 to 2017. The total number of SEA firms that already had their own ESG Scores by Thomson Reuters ESG Research over the period 20112017 was 145 firms per year. The firm count for each country was Indonesia, 25 firms (17,24\%); Malaysia, 41 firms $(28,28 \%)$; Thailand, 17 firms $(11,72 \%)$; Singapore, 42 firms (28,97\%); and the Philippines, 20 firms $(13,79 \%)$. This sample made 1,015 firm-year observations. This number was reduced by missing financial variables and left a usable sample of 995 firmyear observations.

\subsection{Variables}

All variables used in this research were obtained from Thomson Reuters (Datastream and ESG Research).

\subsubsection{Dependent Variables: Market Risk}

Risk is defined as the uncertainty of an outcome or event, especially events related to the future (Brigham \& Gapenski, as cited in Orlitzky \& Benjamin, 2001). Firm risk is defined as inherent risk in a firm's operation as the outcome of internal or external factors that can affect the firm's profitability (Jo \& Na, 2012). Firm risk measures a firm's financial performance fluctuation from time to time (Orlitzky \& Benjamin, 2001). These fluctuations may occur in stock prices (market risk) or in internal accounting returns (accounting risks) such as ROA fluctuations or ROE. Thus, based on the measurement, the risk to the company is divided into market risk and accounting risk (Orlitzky \& Benjamin, 2001). Since this study try to investigate the ESG investing issue, we therefore focus on market risk (RISK). Previous research measured this risk by using the annualized standard deviation of daily stock returns over the previous 12 months (Jo \& Na, 2012; Orlitzky \& Benjamin, 2001).

Market risk could also be further classified into systematic risk (BETA) and nonsystematic risk (IR). Systematic risk is the risk that arises from general economic or market conditions, such as inflation, exchange rates, etc. (Bodie, Kane, \& Marcus, 2013). It is also called nondiversifiable risk. It depends on a company's sensitivity to changes in market returns. Thus, we measured systematic risk by calculating the firm's Beta based on the standard Capital Asset Pricing Model (CAPM) using the regression of daily excess returns of each country's market over the year (Benlemlih et al., 2016).

Nonsystematic risk or Idiosyncratic risk is a firmspecific risk that is not affected by the market movement, usually ties with its firm strategy. We measure a firm's 
idiosyncratic risk as the standard deviation of residuals from CAPM based on daily stock returns (Benlemlih et al., 2016). The CAPM equation used in this research was:

$$
R_{i t}-R_{f t}=\alpha_{i}+\beta_{i}\left(R_{m t}-R_{f t}\right)+e_{i}
$$

Where $\mathrm{R}_{\mathrm{it}}$ is the return on security $i$ for day $t, \mathrm{R}_{\mathrm{ft}}$ is the risk-free rate for day $t, \alpha_{i}$ is the intercept term, $\beta_{i}$ is the systematic risk of security $i$ (BETA), $\mathrm{R}_{\mathrm{mt}}$ is the return on the market $m$ for day $t$, and $e$ is the error term.

\subsubsection{Independent Variables: ESG Scores}

ESG Scores are obtained from the Thomson Reuters ESG Research database, which has covered ESG Scores for firms around the world since 2002. Three scores were used in this research. The first score is ESG Score (ESG), which measures a company's ESG performance based on public-domain reported data (Thomson Reuters, 2017). The second is ESG Controversy Score (CONT), which is calculated based on 23 ESG controversy topics. If a scandal occurs during the year, the overall ESG Controversy Score will be affected. The higher the ESG Controversy Score, the more the firm is involved in controversial issues. The last score is ESG Combined Score (COMB), which provides a comprehensive scoring of a company's ESG performance.

\subsubsection{Control Variables}

We included a number of control variables that can affect the individual firm's risk. We controlled for firm size $(S I Z E)$ as measured by natural logarithm to total assets because prior studies showed that large firms are less exposed to risk because they are more able to manage risk, especially in times of high volatility (Jo \& Na, 2012). Therefore, we expected a negative relationship to exist between size and firm risk. We also controlled for marketto-book ratio (MTB). Based on a study by Lewellen (1999), analysts tend to associate firms with low marketto-book ratio with a higher exposure to risk. This also means the firm would be riskier. Thus, we expected a negative relationship between risk and $M T B$. We also controlled for leverage ( $L E V)$, which was measured by the total debt to total assets ratio. Lewellen (1999) also suggested that the firm that has high leverage in its structure would be exposed to higher risk. Thus, we expected a positive association between leverage and risk. Next, we controlled for profitability that is measured by ROA since previous findings suggested that more profitable firms are less risky (Jo \& Na, 2012). Prior studies suggested that the higher the asset growth of a firm, the riskier the firm is (Jo \& Na, 2012); thus, we also controlled for asset growth $(A S G R)$ as measured by total assets in year $t$ minus total assets in year $t-1$ divided by total assets in year $t-1$. We also employed country-level control variables that measured the law enforcement of governance in each country, titled "Rule of Law" ( $R O L)$. $R O L$ scores for each country were obtained from the Worldwide Governance Indicators (Kaufman \& Kray, 2017) that has covered scoring for governance indicators in many countries around the world since 2002.

\subsection{Models}

Following Benlemlih et al. (2016), we used this model to test our hypotheses.

$$
\begin{array}{r}
\text { Firm Risk }_{i t}=\alpha_{0}+\alpha_{1} \text { ESG Measures } \\
\alpha_{2} \text { MIZE }_{i t}+\alpha_{3} \text { ROA }_{i t}+\alpha_{4} \text { MTB }_{i t}+\alpha_{5} \text { LEV }_{i t}+ \\
\alpha_{6} \text { ASGR }_{i t}+\sum_{j} \alpha_{7} \text { ROL }_{j}+\sum_{q=1}^{12} \alpha_{d} Y E A R_{q 1}+ \\
\varepsilon_{i t}
\end{array}
$$

\section{RESULT AND DISCUSSION}

\subsection{Descriptive Statistics}

Table I shows the descriptive statistics for this research. The descriptive statistics were obtained from data that had previously been winsorized to the $95 \%$ level. Overall, from the data, we can see that the scores and other data among firms in Southeast Asia are widely dispersed, indicating that firms with scales ranging from small to large in Southeast Asia were included in this study.

Table I. Descriptive Statistics

\begin{tabular}{|l|c|c|c|c|c|}
\hline Variable N & Mean & Std. Dev & Min & Maks \\
\hline \multicolumn{7}{|l|}{ Dependent Variable: Risk } \\
\hline RISK & 995 & $24,7 \%$ & 0,089 & $11,9 \%$ & $43,4 \%$ \\
\hline BETA & 995 & 0,760 & 0,476 & $-0,005$ & 1,609 \\
\hline IR & 995 & $22,3 \%$ & 0,084 & $9,9 \%$ & $40,2 \%$ \\
\hline Independent Variable: ESG Score \\
\hline ESG & 995 & 50,10 & 15,85 & 19,77 & 76,24 \\
\hline CONT & 995 & 57,49 & 13,05 & 16,67 & 69,03 \\
\hline COMB & 995 & 48,15 & 15,92 & 19,08 & 75,48 \\
\hline Control Variables & & & \\
\hline SIZE & 995 & 22,58 & 1,38 & 20,14 & 25,13 \\
\hline ROA & 995 & 0,065 & 0,0549 & 0,0043 & 0,2037 \\
\hline LEV & 995 & 0,7451 & 0,6216 & 0,0112 & 2,339 \\
\hline MTB & 995 & 2,78 & 2,58 & 0,6120 & 10,88 \\
\hline ASGR & 995 & 0,088 & 0,099 & $(0,0765)$ & 0,314 \\
\hline ROL & 995 & 7,132 & 2,68 & 2,5 & 10 \\
\hline
\end{tabular}




\subsection{Empirical Results Multivariate Analyses}

The results of regression model are reported in Table II. We regressed the model for each risk measurement. Furthermore we also conduct two variation for ESG score; as an individual ESG score (ESG and CONT) and as an ESG combined score (COMB). Therefore we have 6 combination result of relationship between risk measurement and ESG score. From the regression result in column 1-2, we find that ESG Combined Score and ESG Score are negative and statistically significant (both at the $10 \%$ and $5 \%$ level). Meanwhile, we didn't find any relationship between ESG Controversy Score to total market risk. The regression result in column 3-4 implies that the three measures of ESG didn't affect systematic risk in any way, since none of the regression results are statistically significant. Lastly, the regression result in column 5-6 implies that ESG Combined Score is statistically and negatively significant with idiosyncratic risk at the $10 \%$ level. The same findings were found for ESG Score, which has a significantly negative relationship with idiosyncratic risk, although it is more significant than the ESG Combined Score, which is at the 5\% level. Just like the two other regression models, no relationship has been found between Controversy Score and any indicator of risk. Hence our result showed that all the hypothesis related with ESG Controversy Score were rejected. The ESG Controversy score has no impact for firm's total market risk, systematic risk and idiosyncratic risk. However the ESG Score and the ESG Combined Score were proved could reduce the firm's total market risk and idiosyncratic risk, but not with firm's systematic risk. Other pattern that we found in the results is that the effect of ESG measures on idiosyncratic risk is always stronger than the effect of any ESG measures on total market risk.

\subsection{Sensitivity Analysis}

In this section, we compared the effect of the ESG Controversy Score alone to all risk measures. We wanted to investigate whether the combining of ESG Controversy Score and ESG Score in one model was the cause of the insignificancy of the relationship between ESG Controversy Score and all risk measures. In the previous model, ESG Controversy Score was put into the same model with ESG Score, because ESG Controversy Score and ESG Score are both components of ESG Combined Score. In this additional analysis, we separated all of them into different models. The results are in Table III.

However, after breaking down the model into separate model, we found no significant difference between combining ESG Controversy Score and ESG
Score in a model and separating it. Thus, it can be concluded that the insignificance of ESG Controversy Score to any risk indicators is not caused by the model, but because the indicator itself that has no relationship with risk.

\subsection{Discussion}

This paper examines the link between firms' ESG performance with firm risk (total, systematic, and idiosyncratic risk). First, based on our findings, we can conclude that ESG performance in Southeast Asia significantly and negatively affects total risk. These findings are in line with previous findings in other studies that prove the ESG performance has a significant and negative relationship with total risk (Kumar et al., 2016; Sassen et al., 2016; Luo \& Bhattacharya, 2009; Benlemlih et al., 2016). However, it is only significant at the $10 \%$ level, which might reflect the slow adoption of the ESG trend in corporate strategy in Asia. This study also found that ESG is not linked with systematic risk. Our finding is in line with Benlemlih et al. (2016) that was done in the UK, which also found that ESG does not have any relationship with systematic risk. The Sassen et. al. study (2016) further confirms this. The study argues that systematic risk is more affected by industry specific characteristics, not by firm-specific characteristics; in this case, the systematic risk will be less responsive to ESG compared to other risk proxies. However, this contradicts Albuquerque et al. (2018) that found a negative relationship between ESG and systematic risk. This difference might be the result of the difference in the scores used in the study or even in the regional difference where the study was conducted. Market characteristics in each region might have played a role, where the market in a more developed region could more easily incorporate ESG into its strategy. This study also found a negative and significant relationship between ESG and idiosyncratic risk. This is also in line with studies done by Benlemlih et al. (2016) and Luo \& Bhattacharya (2009).

Overall, the increase in a firm's ESG performance in Southeast Asia, particularly in the ASEAN-5, could lower the total risk, although if we delve deeper, we can see that the increase in ESG performance only affects the idiosyncratic risk. The ESG effect on the idiosyncratic risk then will affect the total risk, since idiosyncratic risk is part of total risk. From the theoretical point of view, these practices imply that companies in the ASEAN- 5 countries treat ESG as part of enlightened value maximization.

The ESG Combined Score also significantly and negatively affects total risk and idiosyncratic risk. When it is separated into ESG Controversy Score and ESG Score, 
we can see that the significance comes from the ESG Score, because ESG Controversy Score-when tested as a standalone-has no relationship with any proxy for risk. This phenomenon might be caused by investors that retrieved the ESG information primarily from sustainability reporting, not from any media coverage (Nelson, 2019). This study can also prove that businesses in Asia are shifting into more sustainable practices. From the theoretical point of view, we could imply that in the ASEAN-5 countries' investors and companies see ESG as part of business ethics. This follows the trend of other regions in the world. It is in line with the survey from Schroders (2017), where $80 \%$ of the investor and business respondents in Asia admit that sustainable investing has become more important in the past 5 years.

Table II. ESG Performance and Firm Risk Regression Outcomes

\begin{tabular}{|c|c|c|c|c|c|c|c|}
\hline \multirow{2}{*}{ Dependent Variable } & \multirow{2}{*}{$+/-$} & \multicolumn{2}{|c|}{ Total Market Risk } & \multicolumn{2}{|c|}{ Systematic Risk } & \multicolumn{2}{|c|}{ Idiosyncratic Risk } \\
\hline & & (1) & (2) & (3) & (4) & (5) & (6) \\
\hline COMB & - & $\begin{array}{l}-0,000333 \\
(0,096)^{*}\end{array}$ & & $\begin{array}{l}0,00072 \\
(0,471)\end{array}$ & & $\begin{array}{l}-0,000358 \\
(0,060)^{*}\end{array}$ & \\
\hline ESG & - & & $\begin{array}{l}-0,000588 \\
(0,024)^{* *}\end{array}$ & & $\begin{array}{l}0,000332 \\
(0,779)\end{array}$ & & $\begin{array}{l}-0,000626 \\
(0,013)^{* *}\end{array}$ \\
\hline CONT & + & & $\begin{array}{l}0,0000596 \\
(0,682)\end{array}$ & & $\begin{array}{l}0,000701 \\
(0,390)\end{array}$ & & $\begin{array}{l}0,0000685 \\
(0,609)\end{array}$ \\
\hline SIZE & - & $\begin{array}{l}-0,0231 \\
(0,079)^{*}\end{array}$ & $\begin{array}{l}-0,0231 \\
(0,078)^{*}\end{array}$ & $\begin{array}{l}0,0762 \\
(0,212)\end{array}$ & $\begin{array}{l}0,0757 \\
(0,213)\end{array}$ & $\begin{array}{l}-0,0243 \\
(0,052)^{*}\end{array}$ & $\begin{array}{l}-0,0244 \\
(0,052)^{*}\end{array}$ \\
\hline ROA & - & $\begin{array}{l}-0,293 \\
(0.000)^{* * * *}\end{array}$ & $\begin{array}{l}-0,294 \\
(0.000)^{* * *}\end{array}$ & $\begin{array}{l}0,215 \\
(0,565)\end{array}$ & $\begin{array}{l}0,213 \\
(0,570)\end{array}$ & $\begin{array}{l}-0,329 \\
(0.000)^{* * *}\end{array}$ & $\begin{array}{l}-0,331 \\
(0.000)^{* * *}\end{array}$ \\
\hline LEV & + & $\begin{array}{l}0,00356 \\
(0,676)\end{array}$ & $\begin{array}{l}0,00368 \\
(0,666)\end{array}$ & $\begin{array}{l}0,0111 \\
(0,811)\end{array}$ & $\begin{array}{l}0,0112 \\
(0,810)\end{array}$ & $\begin{array}{l}0,00368 \\
(0,663)\end{array}$ & $\begin{array}{l}0,00381 \\
(0,651)\end{array}$ \\
\hline MTB & - & $\begin{array}{l}-0,00232 \\
(0,226)\end{array}$ & $\begin{array}{l}-0,00232 \\
(0,223)\end{array}$ & $\begin{array}{l}-0,0189 \\
(0,058)^{*}\end{array}$ & $\begin{array}{l}-0,0189 \\
(0,059)^{*}\end{array}$ & $\begin{array}{l}-0,00215 \\
(0,266)\end{array}$ & $\begin{array}{l}-0,00215 \\
(0,261)\end{array}$ \\
\hline ASGR & + & $\begin{array}{l}0,016 \\
(0,480)\end{array}$ & $\begin{array}{l}0,0153 \\
(0,498)\end{array}$ & $\begin{array}{l}-0,343 \\
(0.000)^{* * *}\end{array}$ & $\begin{array}{l}-0,344 \\
(0.000)^{* * *}\end{array}$ & $\begin{array}{l}0,0196 \\
(0,336)\end{array}$ & $\begin{array}{l}0,0189 \\
(0,353)\end{array}$ \\
\hline ROL & - & $\begin{array}{l}-0,0717 \\
(0,067)^{*}\end{array}$ & $\begin{array}{l}-0,071 \\
(0,071)^{*}\end{array}$ & $\begin{array}{l}0,577 \\
(0.000)^{* * *}\end{array}$ & $\begin{array}{l}0,576 \\
(0.000)^{* * *}\end{array}$ & $\begin{array}{l}-0,0736 \\
(0,060)^{*}\end{array}$ & $\begin{array}{l}-0,0729 \\
(0,064)^{*}\end{array}$ \\
\hline Intercept & & 0,87 & 0,88 & $-1,18$ & $-1,193$ & 0,866 & 0,877 \\
\hline N Observation & & 995 & 995 & 995 & 995 & 995 & 995 \\
\hline N Firms & & 145 & 145 & 145 & 145 & 145 & 145 \\
\hline Prob>chi2 & & 0,0000 & 0,0000 & 0,0000 & 0,0000 & 0,0000 & 0,0000 \\
\hline $\mathbf{R}^{2}(\%)$ & & $29,97 \%$ & $30,10 \%$ & $9,30 \%$ & $9,40 \%$ & $31,56 \%$ & $30,11 \%$ \\
\hline $\operatorname{Adj} R^{2}$ & & $29,05 \%$ & $29,10 \%$ & $8,10 \%$ & $8,10 \%$ & $30,65 \%$ & $29,18 \%$ \\
\hline
\end{tabular}

The mark. *,**, and *** denote statistical significance at the 10,5 , and $1 \%$ levels, respectively 
Table III. Ensitivitty Analysis

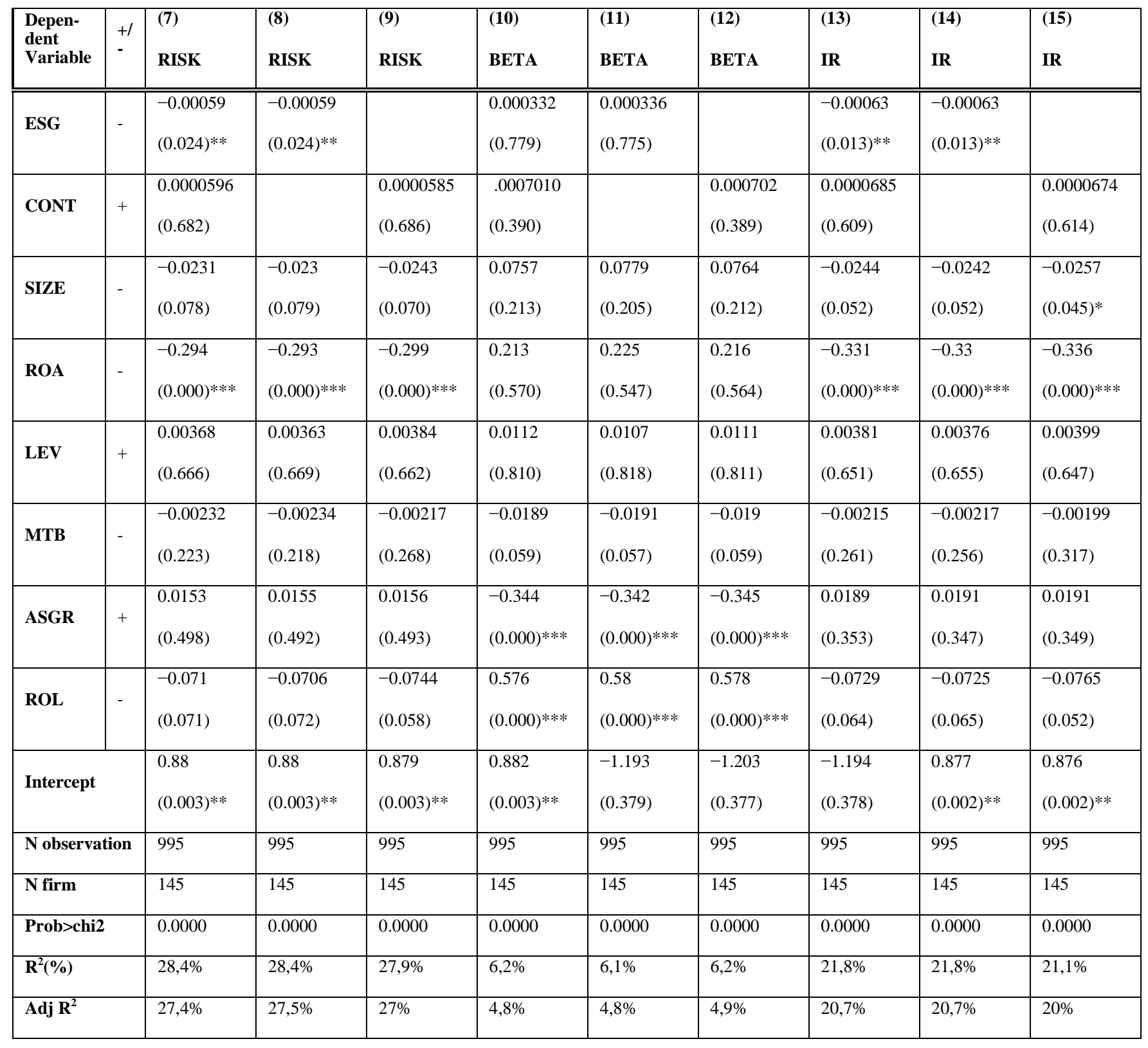

\section{CONCLUSION}

This study analyzes the effect of ESG performance of companies in Southeast Asia as measured by ESG Combined Score, ESG Score, and ESG Controversy Score projected against company risk, either in the form of total corporate risk, systematic risk, or nonsystematic risk. The sample used in this study are open companies listed on the stock exchanges of five Southeast Asian countries, namely
Indonesia, Malaysia, the Philippines, Thailand, and Singapore during the period 2011-2017.

Overall, the model is able to explain the relationship between the dependent variable and the independent variable. Based on the results, we obtained three research findings. First, the ESG performance of companies in the Southeast Asian region as measured by either ESG Score or ESG Combined Score has a significant negative impact 
on the total risk of the firm and the nonsystematic risk of the company. Second, there is no effect on ESG performance of companies in the Southeast Asian region-measured either by ESG Score or ESG Combined Score-against the systematic risk of the company. Third, there is no effect of ESG Controversy Score companies on corporate risk, either against total risk, systematic, or nonsystematic. From our findings, it can be concluded that for companies in Southeast Asia, good corporate ESG performance can decrease the company's risk. Also, if the company's ESG performance is bad, it can also increase the company's risk.

We acknowledge that this study has some limitations. We did not make any distinction between company characteristics based on industry. Yet every industry can have different risk profiles. We used the CAPM model by Sharpe (1964) and Lintner (1965) for measuring risk calculation and did not use the Fama-French's Three Factor Model and the Carhart's Four Factor Model. The two previous models draw considerable criticism from academics compared to the latter two models, which, according to the literature, can predict the yield variation more accurately. This research only looked at the relationship between ESG factors to corporate risk, but we have not seen the influence of each ESG pillar against the three corporate risk proxies, namely environmental, social, and governance pillars. This is because there is no total score for each pillar in the latest Thomson Reuters ESG Research version, but only for ESG Score, ESG Combined Score, and ESG Controversy Score along with the descriptive score of each pillar. However, Thomson Reuters actually provides a weighted count of each pillar that can be used to calculate the final score of each ESG pillar. Further research could be improved based on current research limitations such as adding industry control variables, using other models for risk calculation, and seeking the effect of each pillar on the risk measures.

\section{REFERENCES}

[1] Abdullah, H., \& Valentine, B. (2009). Fundamental and Ethics Theories of Corporate Governance. Middle Eastern Finance and Economic, (4).

[2] Albuquerque, R., Koskinen, Y., \& Zhang, C. (2017). Corporate Social Responsibility and Firm Risk: Theory and Empirical Evidence Corporate Social Responsibility and Firm Risk, December.

[3] Beaver, W. H., Kettler, P., \& Scholes, M. (1970). The Association Between Market Determined and Accounting Determined Risk Measures. The Accounting Review, 45(4), 654-682. https://doi.org/10.2307/244204
[4] Benlemlih, M., Qiu, Y., Shaukat, A., West, B. S., \& Court, S. (2016). Environmental and Social Disclosures and Firm Financial Risk: Evidence from UK Environmental and Social Disclosures and Firm Financial Risk: Evidence from UK. Journal of Business Ethics, 152, 613-626. https://doi.org/https://doi.org/10.1007/s10551-0163285-5

[5] Bodie, Z., Kane, A., \& Marcus, A. J. (2013). Essentials of Investments (9th Edition). New York: McGraw-Hill/Irwin.

[6] Boutin-Dufresne, F., \& Savaria, P. (2004). Corporate Social Responsibility and Financial Risk. Journal of Investing, 13(1), 57-66.

[7] Clark, G. L., Feiner, A., \& Viehs, M. (2015). From the Stockholder to the Stakeholder: How Sustainability Can Drive Financial Outperformance. SSRN Electronic Journal, (March), 63.

[8] Goyal, A., \& Santa-Clara, P. (2001). Idiosyncratic Risk Matters! * Idiosyncratic Risk Matters!

[9] Jensen, M. C. (2001). Value Maximization, Stakeholder Theory, and the Corporate Objective Function.

[10] Jo, H., \& Na, H. (2012). Does CSR Reduce Firm Risk? Evidence from Controversial Industry Sectors. Journal of Business Ethics, 110(4), 441-456. https://doi.org/10.1007/s10551-012-1492-2

[11] Kaufman, D., and Kray, A. (2017). Worldwide Governance Indicator Project, The Worldbank.

[12] Kumar, N. C. A., Smith, C., Badis, L., Wang, N., Ambrosy, P., \& Tavares, R. (2016). ESG Factors and Risk-Adjusted Performance: A New Quantitative Model. Journal of Sustainable Finance \& Investment, 6(4), 292-300. https://doi.org/10.1080/20430795.2016.1234909

[13] Lee, K.-H., Cin, B. C., \& Lee, E. Y. (2016). Environmental Responsibility and Firm Performance: The Application of an Environmental, Social and Governance Model. Business Strategy and the Environment, 25(1), 40-53

[14] Lewellen, J. (1999). The Times Series Relations among Expected Return, Risk and Book-To-Market. Journal of Financial Economics, 54, 5-43

[15] Luo, X., \& Bhattacharya, C. (2009). The Debate over Doing Good: Corporate Social Performance, Strategic Marketing Levers, and Firm-Idiosyncratic 
Risk. Journal of Marketing, 73(6), 198-213. https://doi.org/10.1509/jmkg.73.6.198

[16] Luo, X., \& Bhattacharya, C. (2009). The Debate over Doing Good: Corporate Social Performance, Strategic Marketing Levers, and Firm-Idiosyncratic Risk. Journal of Marketing, 73(6), 198-213. https://doi.org/10.1509/jmkg.73.6.198

[17] Maisonneuve, V. (2017). Mainstreaming ESG Investing in Asia. Eatspring Investments, Singapore.

[18] Mcphail, J. (2014). ESG Disclosure, Corporate Governance and Firm Performance: Empirical evidence from UK, France, Germany, Japan and US markets 2008-2012.

[19] Mentor, M. (2016). The Effects of Corporate Social Responsibility on Financial Performance. Honors in the Major Theses.

[20] Miralles-quir, M., Miralles-quir, L., Miguel, L., \& Gon, V. (2018). The Value Relevance of Environmental, Social, and Governance Performance: The Brazilian Case. Sustainability, 10(3), 574. https://doi.org/10.3390/su10030574

[21] MSCI. (2018). ESG 101: What is ESG Investing?.

[22] Nelson, Mathew. (2017) Is your non-financial performance revealing the true value of your business to investors?, 28. Erns \& Young Global Climate Survey, UK.

[23] Orlitzky, M., \& Benjamin, J. D. (2001). Corporate Social Performance and Firm Risk: A Meta-Analytic Review. Sage Publications, 40, 369-396. https://doi.org/10.9774/GLEAF.4700.2007.sp.00010

[24] Patel, K. (2015). Sustainable Reality: Understanding the Performance of Sustainable Investment Strategies. Institute for Sustainable Investing.
[25] Plumlee, M., Brown, D., Hayes, R. M., \& Marshall, R. S. (2015). Voluntary environmental disclosure quality and firm value: Further evidence. Journal of Accounting and Public Policy, 34(4), 336-361. https://doi.org/10.1016/J.JACCPUBPOL.2015.04.00 4

[26] Retrieved from https://www.msci.com/esginvesting?gclid=CjwKCAjwoKDXBRAAEiwA4xnq v1BJHb-

2F2MkSTRHwQ_RdfJrA5qThiOBftfkuzyzOKsJS7p JXejb8RoC7moQAvD_BwE

[27] Retrieved June 13, 2018, from http://www.eastspring.com/perspectives/mainstreami ng-esg-investing-in-asia

[28] Saint, D. K., \& Tripathi, A. N. (2006). The Shareholder and Stakeholder Theories of Corporate Purpose. Knowledgeworkz Consulting, USA.

[29] Sassen, R., Hinze, A. K., \& Hardeck, I. (2016). Impact of ESG Factors on Firm Risk in Europe. Journal of Business Economics, 86(8), 867-904. https://doi.org/10.1007/s11573-016-0819-3

[30] Schroders (2017), Global Investor Study; Investor Behavior from priority to expectation, Schroders Plc, USA.,

[31] Thompson, F., Tonby, O., \& Vinayak, H. V. (2014). Understanding ASEAN: Seven Things You Need To Know | McKinsey \& Company. Retrieved June 13, 2018 , from https://www.mckinsey.com/industries/publicsector/our-insights/understanding-asean-seventhings-you-need-to-know

[32] Thomson Reuters. (2017). Thomson Reuters ESG Scores, (March), 12. 